\title{
Long-term Outcome of Autologous Hematopoietic Stem Cell Infusion in Cirrhosis: Waning Effect over Time
}

\author{
Mithun Sharma*1, Anand Kulkarni ${ }^{1}$, Mitnala Sasikala ${ }^{2}$, Pramod Kumar ${ }^{1}$, \\ Shasidhar Jaggaiahgari ${ }^{2}$, Kumar Pondugala ${ }^{2}$, Ganesh Jaishetwar ${ }^{3}$, Santosh Darisetty ${ }^{1}$, \\ Nitin Jagtap ${ }^{1}$, Rajesh Gupta ${ }^{1}$, Jagadeesh Rampal Singh ${ }^{1}$, Syeda Fatima ${ }^{1}$, \\ Padaki Nagaraja Rao ${ }^{1}$, Guduru Venkat Rao ${ }^{1}$ and Duvurr Nageshwar Reddy ${ }^{1}$ \\ ${ }^{1}$ Asian Institute of Gastroenterology, Hyderabad, India; ${ }^{2}$ Asian Healthcare Foundation, Hyderabad, India; ${ }^{3}$ Yashoda Hospital, \\ Hyderabad, India
}

\section{Abstract}

Background and Aims: Long-term data on cell-based therapies, including hematopoietic stem cell infusion in cirrhosis, are sparse and lacking. Methods: Patients with cirrhosis of non-viral etiology received either standard-of-care $(n=23)$ or autologous CD34+ cell infusion through the hepatic artery $(n=22)$. Study patients received granulocyte colony-stimulating factor (commonly known as G-CSF) injections at $520 \mu \mathrm{gm}$ per day for 3 days, followed by leukapheresis and CD34+ cell infusion into the hepatic artery. The Control group received standard-of-care treatment. Results: Mean CD34+ cell count on the third day of G-CSF injection was $27.00 \pm 20.43$ cells/ $\mu \mathrm{L} 81.84 \pm 11.99$ viability and purity of $80-90 \%$. Significant improvement in the model of endstage liver disease (commonly known as MELD) score $(15.75 \pm 5.13$ vs. $19.94 \pm 6.68, p=0.04)$ was noted at end of 3 months and 1 year $(15.5 \pm 5.3$ vs. $19.8 \pm 6.4, p=$ $0.04)$ but was not statistically different at end of the second (17.2 \pm 5.5 vs. $20.3 \pm 6.8, p=0.17)$ and third-year $(18.4 \pm$ 6.1 vs. $21.3 \pm 6.4, p=0.25)$. No difference in mortality $(6 / 23$ vs. 5/23) was noted. Conclusions: Autologous CD34+ cell infusion effectively improved liver function and MELD score up to 1 year but the sustained benefit was not maintained at the end of 3 years, possibly due to ongoing progression of the underlying disease.

Citation of this article: Sharma M, Kulkarni A, Sasikala M, Kumar $\mathrm{P}$, Jaggaiahgari $\mathrm{S}$, Pondugala $\mathrm{K}$, et al. Long-term outcome of autologous hematopoietic stem cell infusion in cirrhosis: Waning effect over time. J Clin Transl Hepatol 2020;8(4):385-390. doi: 10.14218/JCTH.2020.00052.

Keywords: Stem cells; Cirrhosis; Hepatic artery; Bridge to liver transplantation. Abbreviations: ALT, alanine aminotransferase; AST, aspartate aminotransferase; $C D$, cluster of differentiation; CLD, chronic liver disease; DDLT, deceased donor liver transplantation; G-CSF, granulocyte colony stimulating factor; GMP, Good Medical Practice; HBA1C, glycosylated hemoglobin; INR, international normalized ratio; LDLT, living donor liver transplantation; MELD, model for end-stage liver disease.

Received: 5 June 2020; Revised: 2 September 2020; Accepted: 27 September 2020

*Correspondence to: Dr. Mithun Sharma, Hepatology, and Liver Transplantation, Asian Institute of Gastroenterology, Hyderabad, India. Tel: +91-4042342234, Fax: +91-4042342334, E-mail: drmithunsharma@gmail.com

\section{Introduction}

The rising incidence of chronic liver disease (CLD) has increased the need for liver transplantation. The unmet need has resulted in numerous studies targeting the regenerative potential of the liver as an alternative or as a bridge to liver transplantation. ${ }^{1,2}$ Stem cells are cells that reside in the human niche and have an intrinsic ability of self-renewal, but they maintain their undifferentiated state and have potency to transform into specialized cells, like hepatocytes. ${ }^{3}$

The capacity of the liver to regenerate can be traced back to the two Greek mythological characters, Tityus and Prometheus, who were both banished to the mountains to suffer and die. In mythology, a vulture used to come and feed on their livers, only to find that the liver regenerated the next day and thereby giving the first documentation of the regenerative potential of the liver. ${ }^{4,5}$ The demonstration that hepatic oval cells can regenerate was shown biologically by hepatocyte proliferation in rats. ${ }^{6}$

Human studies using hematopoietic stem cells identified a subset of CD34+ cells, which have the potential to differentiate into liver cells. These CD34+ cells were identified based on their distinct appearance, immunophenotype, and gene expression. For proof of concept, safety study was first conducted with five patients, opening the doors for further research in this field. ${ }^{7}$ After that, numerous studies have looked into the short-term outcome of infusion of hematopoietic or mesenchymal stem cells in patients with cirrhosis of the liver. ${ }^{8-10}$ However, the route by which stem cells were infused, the method of calculation of the dose of cells, and the stage of liver cirrhosis when these cells were infused were heterogeneous. Studies using granulocyte colony-stimulating factor (G-CSF) alone to mobilize hematopoietic stem cells from bone marrow to the liver have shown an increased number of CD34+ hematopoietic stem cells in the liver tissue in a paired-biopsy study, thereby suggesting that there is a definite increase in the number of stem cells in the liver following mobilization. ${ }^{11}$ Whether mere mobilization of the cells is enough or whether the separation of specific stem cells is required along with direct infusion into the target organ (liver) would yield better results is a matter of debate.

Our previous study with autologous hematopoietic stem cell infusion through the hepatic artery showed significant 
Sharma M. et al: Stem cell in liver disease: Long-term outcome

short-term improvement in model for end-stage disease (MELD) score, serum albumin, and serum creatinine. These benefits were noticed at the beginning of the first month after autologous CD34+ cell infusion and were maintained at 3 and 6 months. ${ }^{12}$

Here, we present the long-term data of the same cohort of patients who underwent autologous hematopoietic stem cell infusion and were followed up for 3 years.

\section{Methods}

Patients with decompensated cirrhosis of the liver having a non-viral etiology, who attended the Liver Clinic of our institute, were screened for eligibility to be enrolled in the study. The screening was carried out between June 2012 and July 2013, and those patients with a MELD score of greater than 14 or a score of greater than 10 with evidence of ascites or hepatic encephalopathy were counseled to undergo liver transplantation. A significant proportion of patients were not willing to undergo transplantation, either due to financial constraints, lack of donor, or a combination of both. These patients were provided an explanation about stem cells and counselled that by enrolment in the study, there may be a beneficial effect on the natural history of their disease. The experimental nature of this modality of treatment was explained in detail, including the concept that they may not benefit at all from this study. Those patients who agreed to be a part of the study were enrolled in the study group. The remaining patients who were willing only to receive deceased donor liver transplantation (DDLT) were included in the liver transplantation waiting list for DDLT and registered with the centralized organ allocation authority of the state. These patients were considered as the control group in the study. A small number of patients who had a first degree-related liver donor underwent liver transplantation. This study was approved by the Institutional Review Board, Institutional Ethics Committee and the Institutional Committee of Stem Cell Research, and informed written consent was obtained from all patients.

\section{Inclusion criteria}

i. Adult patients between 18 to 70 years of age with a MELD score of $>14$ and with no donor or finance for immediate liver transplantation within in the next 3 months;

ii. A MELD score-based life expectancy of at least 3 months;

iii. Ability to give written informed consent.

\section{Exclusion criteria}

i. Any patient with hepatocellular carcinoma or any other malignancy within the last 5 years;

ii. Presence of ongoing infections, including retroviral, hepatitis B or hepatitis C;

iii. Co-existent cardiac and/or pulmonary co-morbidities related or unrelated to liver cirrhosis;

iv. Recent history of upper or lower gastrointestinal bleeding, acute kidney injury or hepatorenal syndrome with the last month;

v. Main portal vein thrombosis, either partial or complete, on cross-sectional imaging;

vi. Patients with a manual platelet count below $50,000 / \mathrm{mm}^{3}$;

vii. Any patient with pregnancy or lactating mothers.

\section{Control group}

Patients between 18-70 years, who were enrolled in the waiting list for DDLT during the study period. Informed consent also was taken from all participants in the control group.

All the patients underwent liver protocol investigations, which included complete hemogram, kidney and liver function tests, serum alpha-fetoprotein, coagulation profile, Dopplerultrasonography of the whole abdomen, and contrastenhanced computed tomography scan along with quantitative estimation of hepatitis B DNA and hepatitis C RNA. Serology tests for syphilis, herpes simplex virus, and cytomegalovirus were conducted, as per protocol. The control group patients were investigated and treated with standard-of-care treatment for liver cirrhosis, which included diuretics, lactulose, beta-blockers, and low salt ( $<2 \mathrm{~g}$ of sodium chloride) and high-protein diet.

The study was approved by the Asian Institute of Gastroenterology Institutional Review Board, Asian Institute of Gastroenterology Ethics Committee, and the Institutional Committee of Stem cell Research, which was registered with the National Apex Committee for stem cell research in India. The study was registered with the clinical trial registry of India (CTRI/2017/11/010429).

\section{Methodology}

Study group patients received G-CSF at $520 \mu \mathrm{g} /$ day (Neupogen, Filgrastim, Roche) for 3 consecutive days, in an effort to mobilize the hematopoietic stem cells' bone marrow niche to the peripheral circulation. Serial monitoring of complete blood counts was carried out, along with liver and kidney function tests. Doppler ultrasonography of the abdomen was done on the third day. Any adverse effects due to administration of GCSF, like fever, symptomatic increase in spleen size and sepsis, were documented and reported. The estimation of serum CD34+ cells was measured daily and $1 \mathrm{~h}$ before leukapheresis. A predefined level of greater than 2 cells $/ \mu \mathrm{L}$ was achieved. For leukapheresis, a central line was secured, and $1 \mathrm{~h}$ after the third dose of G-CSF, the patient was moved to the phlebotomy unit. Leukapheresis, under the supervision of a hematologist, was done using an MCS-3P magnetic cell separator (Hemaneics, USA). The amount of peripheral blood collected after leukapheresis varied between $30 \mathrm{~mL}$ to $60 \mathrm{~mL}$. Side effects related to leukapheresis, like hypotension, tachycardia, shortness of breath, etc., were documented, and corrective measures were taken as per standard operating procedures. The leukapheresis product underwent mononuclear cell isolation in a cleanroom in a Good Medical Practice (commonly known as GMP)-certified laboratory of the institute.

Hi-Sep method (HiSep LSM1077, LS001; Himedia Laboratories, India) was used for mono-nuclear cell isolation, with washing with phosphate buffered saline and diluting with CliniMACS buffer (Miltenyi Biotech, GmbH, Germany). These cells underwent centrifugation and incubation with $\mathrm{CD} 34^{+}$ labeled monoclonal antibodies microbeads (MACS; Miltenyi Biotech) for $30 \mathrm{~m}$. CliniMACS buffer was used to wash these cells, which were then processed in a CliniMACs cell separator. A high-gradient magnetic field was used to separate the CD34 + cells. The cell adequacy was calculated, and viability of the cells was assessed using the trypan blue dye exclusion method. Cell viability was higher than $80 \%$ in all cases. 
Flow cytometry was used to ascertain cell purity. The CD34+ hematopoietic stem cells were diluted with $10 \mathrm{~mL}$ of phosphate buffered saline supplemented with $2 \%$ human serum albumin and dispatched for use on the same day, within $1 \mathrm{~h}$. The hepatic artery was catheterized through the femoral route under fluoroscopic guidance by the interventional radiologist and infused into the hepatic artery. The patients were observed overnight and discharged the subsequent day, after a screening Doppler ultrasonogram to rule-out hepatic artery thrombosis. Any procedure-related adverse effects, like pain (recorded by visual analog scale) or bleeding from the femoral catheterization site, etc., were noted.

\section{Follow-up visits of patients}

Weekly follow-up of the patients was carried out through the first months, followed by quarterly evaluation for 1 year and then half-yearly assessment for the subsequent 3 years. During each follow-up visit, the patient underwent a complete hemogram, along with renal and liver function test, serum alpha-fetoprotein test, and Doppler ultrasonography of the abdomen. The presence or appearance of any new complaints was noted. As stem cells have a potential for carcinogenesis, any suspicious nodule or rise in alpha-fetoprotein was further evaluated by cross-sectional imaging to rule-out hepatocellular carcinoma. Worsening of ascites, need for large-volume paracentesis, evidence of spontaneous bacterial peritonitis late-onset or recurrent hepatic encephalopathy, an/or any gastrointestinal bleed was noted. Patients in the control arm underwent similar follow-up visits. For both groups, any emergency hospital visits, either to our center or any hospital locally, were noted.

\section{Statistical analysis}

A comparison of the clinical and laboratory findings was performed at the end of 1 month, 3 months and 3 years, to assess the long-term outcome. All nominal values were expressed as mean with standard deviation and as median with range. Fisher's exact test was used for categorical variables, and a two-tailed $p$-value of $<0.05$ was considered to be significant. GraphPad software 2019 was used for this per-protocol statistical analysis.

\section{Results}

One hundred patients were screened for eligibility to be enrolled in the study. The inclusion criteria were not met by 30 patients, while another 25 patients refused to participate in the study. Two patients in the study group underwent living donor liver transplantation (LDLT), as they were able to find a suitable donor. Another patient died due to hepatorenal syndrome, and one patient was lost to follow up in the initial 1-3 months period. Out of the 23 patients in the control arm (liver transplantation waiting list), there were no dropouts at the end of 1 month. However, between 1 and 3 months, two patients died due to sepsis and one due to hepatorenal syndrome. Another patient in the control group underwent DDLT, while two patients were lost to follow-up. In the initial data analysis that was published in $2015,{ }^{12}$ there were 17 and 18 patients in the control and study groups in the per-protocol analysis. These patients have now been followed up to the end of 3 years. During this extension period of the study, a total of $6 / 23$ patients in the study group and $5 / 23$ in the control group died due to complications of portal hypertension. Sepsis was the most common cause of death (four patients in both groups. Two patients in the study group and one patient in control died due to acute upper gastrointestinal bleed. Three patients in the control group underwent liver transplantation while on the waiting list, as shown in the consort diagram. During the follow-up of 3 years, two patients were lost to follow-up in the control group and one in the study group. So, in the final analysis at the end of 3 years, there were 13 patients in the study group and 12 in the control group.

In the control and study groups, at the beginning of the study, the cause of cirrhosis was cryptogenic in $18(78.2 \%)$ and $16(72.72 \%)$, and alcohol use disorder-related in 5 $(21.7 \%)$ and $6(27.27 \%)$ respectively. In the final analysis at the end of 3 years, there were $9 / 12$ (75\%) cryptogenic and $4 / 12(25 \%)$ alcohol use disorder-related cirrhosis cases in the study group, and 8/12 (66.7\%) and 4/12 (33.3\%) respectively in the control arm.

There was no difference in the baseline characteristics at the initiation of the study, nor when the primary analysis was done at the end of 3 months nor at the end of the study at 2 years. The MELD score in both groups was similar. Median alcohol abstinence was 7 months (range, 5-11 months) in the control group. In comparison, it was 6 months (range, 4-12 months) in the study group, and all the patients maintained the alcohol abstinence during the study period. Seven patients in the control group and six in the study group had well-controlled type 2 diabetes mellitus [mean glycosylated hemoglobin (HBA1c): 6.45 (range, 5.3-8.3) and 6.63 (range, 5.1-9), respectively]. Ascites was present in 95.6\% $(n=22)$ and $100 \%(n=22)$ of patients in the control group and study group respectively. Patients with refractory ascites requiring therapeutic paracentesis for respiratory easement and impaired quality of life was $22.7 \%$ and $21.7 \%$ respectively in the study and control groups. Limitation of an increase in diuretic dose due to adverse effects was the cause of refractory ascites in all patients. Overt hepatic encephalopathy within the last 3 months before enrolment in the study was $26 \%(n=6)$ and $7(31.81 \% ; n=7)$ in the control and study groups respectively.

Baseline CD34+ cell count (cells/ $\mu$ L) before G-CSF administration was $2.3 \pm 2.56$ (mean \pm standard deviation). Cell viability at baseline was $48.17 \pm 23.95 \%$. Peripheral CD34+ cell count measured on the third day after G-CSF infusion was $27.00 \pm 20.43$ (cells $/ \mu \mathrm{L}$ ), and the cell viability was improved to a value of $81.84 \pm 11.99 \%$. Cell purity varied between $80 \%$ and $90 \%$ among all patients. A minimum of $1 \times 10^{6}$ hematopoietic stem cells per $\mathrm{kg}$ dry body weight of the patient were infused through the hepatic artery.

\section{Results after CD34+ cell infusion}

Primary endpoint analysis of the original published data revealed an increase in the mean serum albumin in the study group $(2.83 \pm 0.36$ vs. $2.43 \pm 0.42, p=0.001)$, which was not maintained at the end of the first year but showed statistically significant improvement at the end of second year. This improvement seen between the first and second year was not maintained at the end of the third year, as shown in Figure 2 (Table 2) when compared with controls. Further, at 3 months, significant improvement in serum creatinine was noted in the study group $(0.96 \pm 0.33$ vs. $1.42 \pm$ $0.70, p=0.01)$, which was not maintained at any other point 
Sharma M. et al: Stem cell in liver disease: Long-term outcome

during the study period, as shown in Table 2. Serum bilirubin, alanine aminotransferase (ALT), and aspartate aminotransferase (AST) did not show any significant differences. Platelet count and international normalized ratio (commonly referred to as INR) showed some improvement but did not reach statistical significance at any point in time. However, when these patients were followed-up for 3 years, there was no difference in the MELD score and mortality (6/23 vs. $5 / 23)$ between the two groups.

There was a significant improvement in the MELD score $(15.75 \pm 5.13$ vs. $19.94 \pm 6.68, p=0.04)$ at the end of 3 months. When these patients were followed-up for 3 years, the improvement in MELD score was maintained at the end of 1 year $(15.5 \pm 5.3$ vs. $19.8 \pm 6.4, p=0.04)$ but was not statistically different at the end of 2 years ( $17.2 \pm 5.5$ vs. 20.3 $\pm 6.8, p=0.17)$ and upon final analysis at the end of the third year $(18.4 \pm 6.1$ vs. $21.3 \pm 6.4, p=0.25)$. Though there was no difference in the mortality $(6 / 23$ vs. $5 / 23)$ between the two groups, the maximum number of deaths was three in each group, occurring between the second and third years.

The most frequent cause of death in both groups was sepsis, followed by one case of upper gastrointestinal bleeding. Patients in both the groups were regularly followed-up with screening endoscopy, and the need for endoscopic variceal ligation was similar in the two groups. No case of new-onset development of gastric varices was noted in our series. The incidence of hepatic encephalopathy was also not different between the two groups (study $3 / 12$ vs. control 4/13).

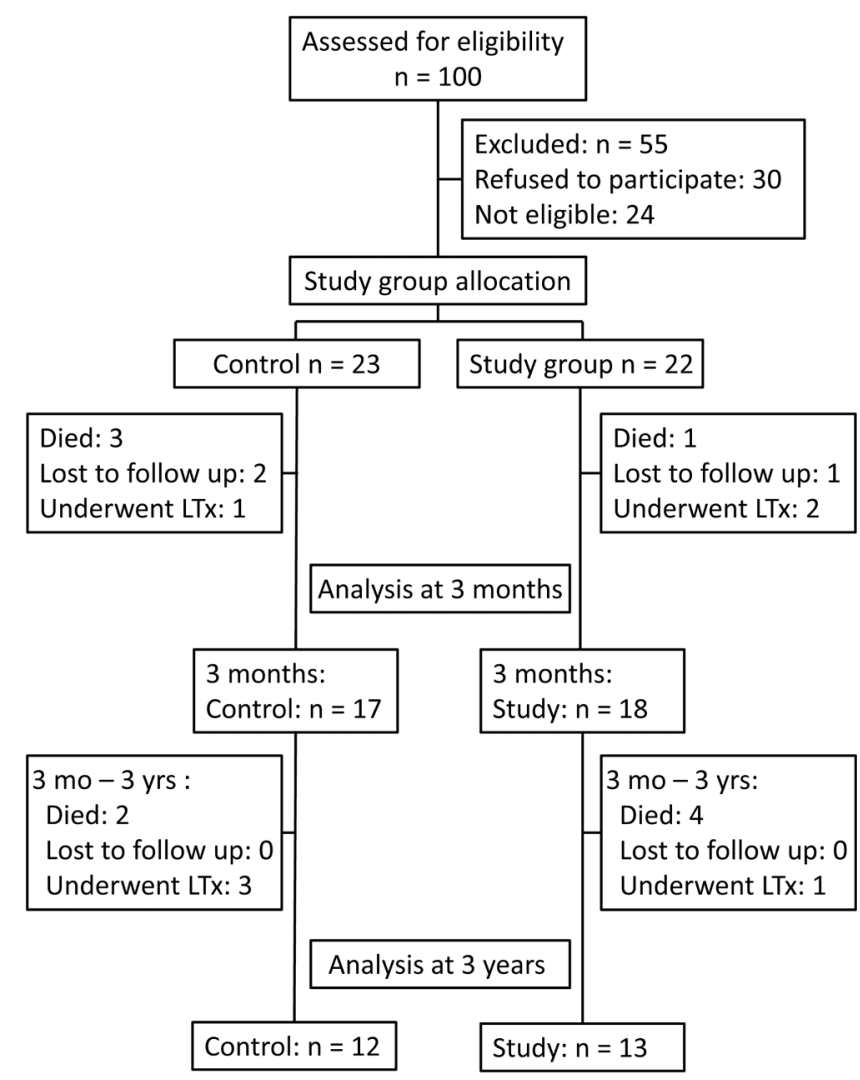

Fig. 1. Consort flow diagram showing patients at the time of recruitment and at the end of 3 years.

Abbreviation: LTx: Liver transplantation.
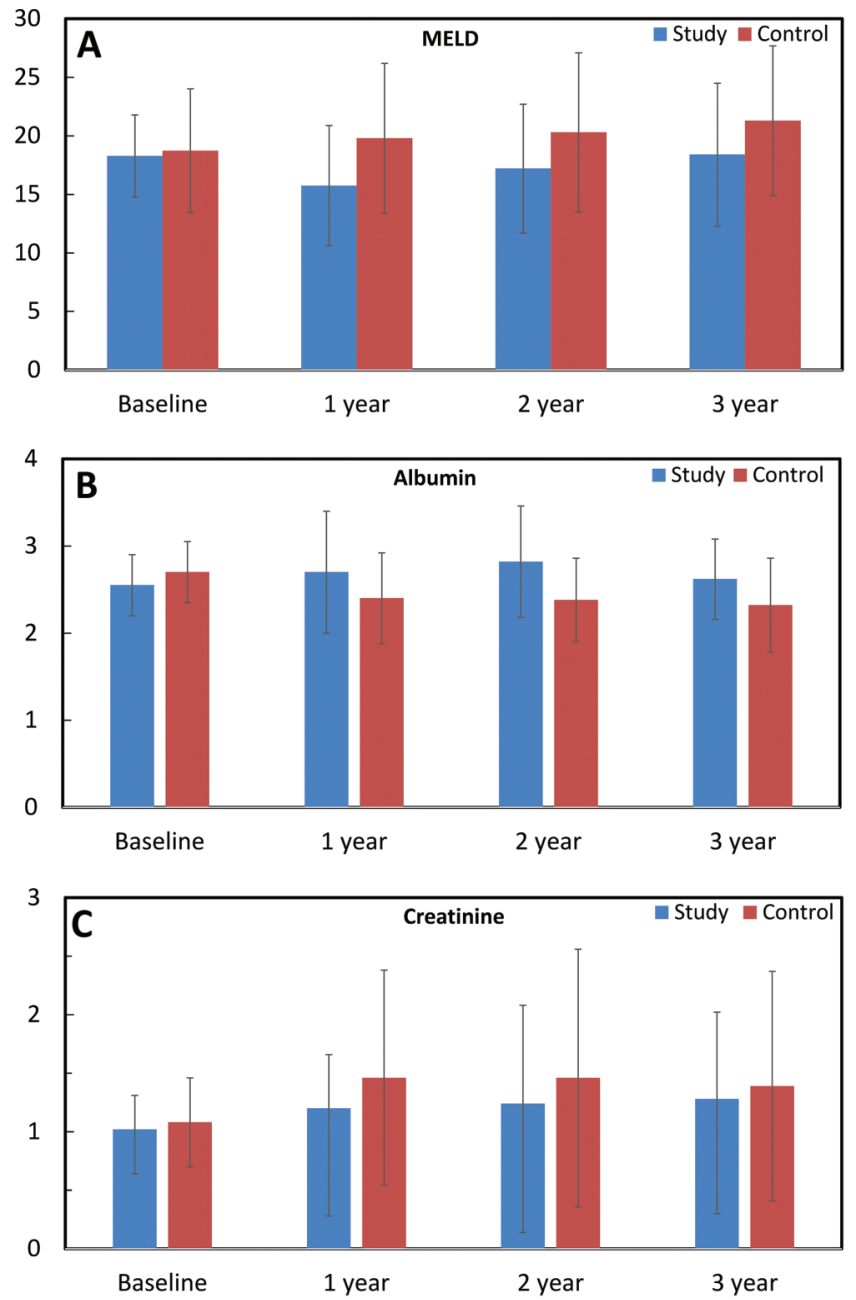

Fig. 2. Improvements. (A) The MELD improvement was maintained at 1 year. (B) Albumin improvement was noted at end of 2 years. (C) No difference in serum creatinine was noted in long-term outcome.

Abbreviation: MELD: Model for end-stage liver disease.

\section{Discussion}

Autologous CD34+ cell infusion is a minimally manipulated cellbased procedure that is safe and improves liver function in the short term, and has been suggested to serve as a bridge to liver transplantation. ${ }^{12}$ But, all studies to date have published their outcomes at a maximum of up to the end of 3 to 6 months. ${ }^{13-15}$ No studies have mentioned the long-term outcome of these patients after the end of the short study period.

A recent retrospective study that used peripheral mobilized stem cell infusion in patients with decompensated cirrhosis assessed a 5-year outcome. The study found that after propensity score matching, survival was significantly higher in patients receiving stem cell infusion $(71.2 \%$ vs. $52.1 \%, p=0.001$ ) than in the control group. ${ }^{16}$ The beneficial effect of this study, when compared with our research, could be due to the patient population having had a lower ChildPugh score, and the majority of the patients being without ascites. So, it could be hypothesized that if stem cells are used early in the course of the natural history of cirrhosis, when the inflammatory milieu ${ }^{17}$ of the liver is still less 
Sharma M. et al: Stem cell in liver disease: Long-term outcome

Table 1. Baseline characteristics at recruitment of the control and study groups

\begin{tabular}{llll}
\hline Parameter & Control group, $n=23$ & Study group, $n=22$ & $p$ value \\
\hline Age in years & $47.35 \pm 12.54$ & $48.91 \pm 9.25$ & 0.62 \\
Sex, Male:Female & $20: 3$ & $16: 6$ & 0.072 \\
Hemoglobin, g/dL & $9.29 \pm 1.86$ & $9.15 \pm 1.60$ & 0.79 \\
Platelet count, lakh/mm 3 & $1.1 \pm 0.72$ & 0.24 \\
Total bilirubin, $\mathrm{mg} / \mathrm{dL}$ & $0.92 \pm 0.27$ & $3.55 \pm 2.12$ & 0.21 \\
Albumin, $\mathrm{mg} / \mathrm{dL}$ & $4.78 \pm 4.06$ & $2.55 \pm 0.35$ & 0.16 \\
INR & $2.7 \pm 0.35$ & $1.80 \pm 0.52$ & 0.62 \\
Serum creatinine, $\mathrm{mg} / \mathrm{dL}$ & $1.72 \pm 0.53$ & $1.02 \pm 0.29$ & 0.56 \\
MELD score & $1.08 \pm 0.38$ & $18.28 \pm 3.50$ & 0.74 \\
\hline
\end{tabular}

Abbreviations: INR, international normalized ratio; MELD, model for end-stage liver disease.

Table 2. Results comparison at different time points after autologous hematopoietic stem cell infusion

\begin{tabular}{|c|c|c|c|c|}
\hline Follow up parameter & Three months & One year & Two year & Three year \\
\hline \multicolumn{5}{|l|}{ MELD score } \\
\hline Study group & $15.75 \pm 5.13$ & $15.75 \pm 5.13$ & $17.2 \pm 5.5$ & $18.4 \pm 6.1$ \\
\hline Control group & $19.94 \pm 6.68$ & $19.8 \pm 6.4$ & $20.3 \pm 6.8$ & $21.3 \pm 6.4$ \\
\hline$p$-value & 0.04 & 0.04 & 0.17 & 0.25 \\
\hline \multicolumn{5}{|l|}{ Albumin, mg/dL } \\
\hline Study group & $2.83 \pm 0.36$ & $2.7 \pm 0.7$ & $2.82 \pm 0.64$ & $2.62 \pm 0.46$ \\
\hline Control group & $2.43 \pm 0.42$ & $2.4 \pm 0.52$ & $2.38 \pm 0.48$ & $2.32 \pm 0.54$ \\
\hline$p$-value & 0.001 & 0.17 & 0.03 & 0.14 \\
\hline \multicolumn{5}{|l|}{ Creatinine, mg/dL } \\
\hline Study group & $0.96 \pm 0.33$ & $1.2 \pm 0.46$ & $1.24 \pm 0.84$ & $1.28 \pm 0.74$ \\
\hline Control group & $1.42 \pm 0.70$ & $1.46 \pm 0.92$ & $1.46 \pm 1.1$ & $1.39 \pm 0.98$ \\
\hline$p$-value & 0.01 & 0.42 & 0.461 & 0.78 \\
\hline
\end{tabular}

hostile to the mobilized or infused stem cells, the regenerative power of the cells could be better. This theory needs to be validated in a prospective randomized trial with paired-biopsies taken pre- and post-stem cell infusion to document increase in the number of stem cells in the liver tissue. The study also did not record any adverse effect of stem cell infusion in the large cohort of patients.

Though initial isolated reports in stem cell studies have reported some adverse effects, like splenomegaly, splenic rupture, and hepatic artery thrombosis, multiple other studies, including randomized control trials, have not found any adverse effects on these patients. However, a multicenter study that did not see any improvement in MELD score and liver function when they compared peripheral CD133+ stem cell infusion mobilized by G-GSF compared to the group receiving G-CSF alone standard-of-care in compensated cirrhosis reported increased adverse effects. ${ }^{18}$ The study also reported a significant worsening of ascites in the stem cell infusion group. As the majority of the patients were compensated, the development of ascites could have been a part of the natural history of cirrhosis, or a precipitating factor may be caused by acute-on-chronic liver failure, which was not addressed in the study. Besides, that study had used an infusion of stem cells through a peripheral vein and the percent- age of the cells that reached the hepatic tissue remains unknown as there was no way the cells could be tracked. There was no paired biopsy to document homing-in of the stem cells. ${ }^{19}$ Besides, as three doses of CD133+ hematopoietic stem cell infusion at a dose of $0.2 \times 10^{6}$ cells per $\mathrm{kg}$ on days 5, 30 and 60, was used, as multiple infusions, then comparing the results and extrapolating the same to studies with single infusion and different dosing is not correct. ${ }^{20}$

Long-term outcomes of autologous stem cell infusion have been studied in another retrospective study, which involved 23 patients undergoing stem cell infusion. Though the overall mortality was less in the stem cell group (55.1\% vs. $73.9 \%$ ), there was no significant difference found in the 10 -year longterm survival rate $(p>0.05)$. There was also a higher incidence of hepatocellular carcinoma in stem cell patients (47.8\% vs. $21.7 \%, p<0.05) .{ }^{21}$ Though theoretically, there is a possibility of uncontrolled malignant proliferation of an aged stem cell niche, ${ }^{22}$ the development of hepatocellular carcinoma in a 10-year period could develop as a part of the natural history. This needs further investigation, though a close watch on the development of hepatocellular carcinoma is always required following any cell-based therapy. ${ }^{23}$

Despite multiple studies, results with isolated hematopoietic stem cell or mesenchymal stem cell infusion in cirrhosis 
have not shown very promising long-term results. The questions of whether it is the wrong timing of injections or whether the cells get destroyed in the hepatic tissue have paved the way for ongoing study on the combination of mesenchymal and hematopoietic stem cells, as the former has an immunomodulatory effect ${ }^{24,25}$ which can possibly benefit the higher regenerative potentials of the hematopoietic stem cells.

One of the drawbacks of this study was the lack of pairedbiopsies to demonstrate the homing-in of the stem cells or to demonstrate an increase in the number of CD34+ cells in the liver tissue. Unfortunately, there is no tracking system by which we can track these infused cells once they are injected. Since this was a long-term data study, multiple biopsies would have been needed at different times, which would have not been practical or feasible.

In conclusion, autologous hematopoietic stem cell infusion in patients with cirrhosis is still considered a safe procedure, despite isolated reports on safety. It is promising to serve as a bridge to liver transplantation. Since cirrhosis is an ongoing process, the answer to whether or not repeated infusions will help (the current evidence does not support it) requires further studies. Combination stem cell therapy or hepatic organoids and mini-liver development in laboratories contain a lot of promise. ${ }^{26,27}$

\section{Conflict of interest}

The authors have no conflict of interests related to this publication.

\section{Funding}

The study was funded by the Asian Healthcare Foundation and Asian Institute of Gastroenterology, Hyderabad, India.

\section{Author contributions}

Conceptualized and designed the study (MS, MiS, PNR, DNR), wrote the manuscript (MS, MiS), contributed to data collection, patient recruitment and follow-up (NJ, $A K, P K, R G)$, involved in stem-cell harvesting and infusion (SJ, KP, SD, GJ), designed the figures (NJ, AK), analyzed the data (SF, PNR), critically reviewed and provided intellectual input to the paper (DNR, PNR, GVR, MS, MiS).

\section{References}

[1] De A, Kumari S, Singh A, Kaur A, Sharma R, Bhalla A, et al. Multiple cycles of granulocyte colony-stimulating factor increase survival times of patients with decompensated cirrhosis in a randomized trial. Clin Gastroenterol Hepatol 2020. doi: 10.1016/j.cgh.2020.02.022.

[2] Kwon YK, Etesami K, Genyk Y. Should living donor liver transplant selection be subject to the same restrictions as deceased donor transplant? Curr Opin Organ Transplant 2020;25:47-51. doi: 10.1097/MOT.0000000000000728.

[3] Alessandra S, Rossi L. Planarian stem cell heterogeneity. Adv Exp Med Biol 2019;1123:39-54. doi: 10.1007/978-3-030-11096-3 4

[4] Tiniakos DG, Kandilis A, Geller SA. Tityus: a forgotten myth of liver regeneration. J Hepatol 2010;53:357-361. doi: 10.1016/j.jhep.2010.02.032.

[5] Chen TS, Chen PS. The myth of Prometheus and the liver. J R Soc Med 1994; 87:754-755.

[6] Petersen BE, Goff JP, Greenberger JS, Michalopoulos GK. Hepatic oval cells express the hematopoietic stem cell marker Thy-1 in the rat. Hepatology 1998;27:433-445. doi: 10.1002/hep.510270218.

[7] Gordon MY, Levicar N, Pai M, Bachellier P, Dimarakis I, Al-Allaf F, et al. Characterization and clinical application of human CD34+ stem/progenitor cell populations mobilized into the blood by granulocyte colony-stimulating factor. Stem Cells 2006;24:1822-1830. doi: 10.1634/stemcells.2005-0629.
[8] Spahr L, Lambert JF, Rubbia-Brandt L, Chalandon Y, Frossard JL, Giostra E, et al. Granulocyte-colony stimulating factor induces proliferation of hepatic progenitors in alcoholic steatohepatitis: a randomized trial. Hepatology 2008; 48:221-229. doi: 10.1002/hep.22317.

[9] Mohamadnejad M, Namiri M, Bagheri M, Hashemi SM, Ghanaati H, Zare Mehrjardi $\mathrm{N}$, et al. Phase 1 human trial of autologous bone marrow-hematopoietic stem cell transplantation in patients with decompensated cirrhosis. World J Gastroenterol 2007;13:3359-3363. doi: 10.3748/wjg.v13.i24.3359.

[10] Pai M, Zacharoulis D, Milicevic MN, Helmy S, Jiao LR, Levicar N, et al. Autologous infusion of expanded mobilized adult bone marrow-derived CD34+ cells into patients with alcoholic liver cirrhosis. Am J Gastroenterol 2008; 103:1952-1958. doi: 10.1111/j.1572-0241.2008.01993.x.

[11] Garg V, Garg H, Khan A, Trehanpati N, Kumar A, Sharma BC, et al. Granulocyte colony-stimulating factor mobilizes CD34(+) cells and improves survival of patients with acute-on-chronic liver failure. Gastroenterology 2012;142:505-512.e1. doi: 10.1053/j.gastro.2011.11.027.

[12] Sharma M, Rao PN, Sasikala M, Kuncharam MR, Reddy C, Gokak V, et al. Autologous mobilized peripheral blood $\mathrm{CD} 34(+)$ cell infusion in non-viral decompensated liver cirrhosis. World J Gastroenterol 2015;21:7264-7271. doi: 10.3748 /wjg.v21.i23.7264.

[13] Gupta H, Youn GS, Han SH, Shin MJ, Yoon SJ, Han DH, et al. Responserelated factors of bone marrow-derived mesenchymal stem cells transplantation in patients with alcoholic cirrhosis. J Clin Med 2019;8:862. doi: 10. 3390/jcm8060862.

[14] Yu SJ, Yoon JH, Kim W, Lee JM, Lee YB, Cho Y, et al. Ultrasound-guided percutaneous portal transplantation of peripheral blood monocytes in patients with liver cirrhosis. Korean J Intern Med 2017;32:261-268. doi: $10.3904 / \mathrm{kjim} .2015 .267$.

[15] Mohamadnejad M, Vosough M, Moossavi S, Nikfam S, Mardpour S, Akhlaghpoor $\mathrm{S}$, et al. Intraportal infusion of bone marrow mononuclear or CD133+ cells in patients with decompensated cirrhosis: A double-blind randomized controlled trial. Stem Cells Transl Med 2016;5:87-94. doi: 10.5966/sctm. 2015-0004.

[16] Guo C, Guo G, Zhou X, Chen Y, Han Z, Yang C, et al. Long-term outcomes of autologous peripheral blood stem cell transplantation in patients with cirrhosis. Clin Gastroenterol Hepatol 2019;17:1175-1182.e2. doi: 10.1016/j.cgh. 2018.10.034.

[17] Monteiro S, Grandt J, Uschner FE, Kimer N, Madsen JL, Schierwagen R, et al. Differential inflammasome activation predisposes to acute-on-chronic liver failure in human and experimental cirrhosis with and without previous decompensation. Gut 2020. doi: 10.1136/gutjnl-2019-320170.

[18] Newsome PN, Fox R, King AL, Barton D, Than NN, Moore J, et al. Granulocyte colony-stimulating factor and autologous CD133-positive stem-cell therapy in liver cirrhosis (REALISTIC): an open-label, randomised, controlled phase 2 trial. Lancet Gastroenterol Hepatol 2018;3:25-36. doi: 10.1016/S24681253(17)30326-6

[19] Noorwali A, Faidah M, Ahmed N, Bima A. Tracking iron oxide labelled mesenchymal stem cells(MSCs) using magnetic resonance imaging (MRI) in a rat model of hepatic cirrhosis. Bioinformation 2019;15:1-10. doi: 10. $6026 / 97320630015001$.

[20] Wu CX, Wang D, Cai Y, Luo AR, Sun H. Effect of autologous bone marrow stem cell therapy in patients with liver cirrhosis: A meta-analysis. J Clin Transl Hepatol 2019;7:238-248. doi: 10.14218/JCTH.2019.00008.

[21] Wang MF, Li YB, Gao XJ, Zhang HY, Lin S, Zhu YY. Efficacy and safety of autologous stem cell transplantation for decompensated liver cirrhosis: A retrospective cohort study. World J Stem Cells 2018;10:138-145. doi: 10. 4252/wjsc.v10.i10.138

[22] Henry CJ, Casás-Selves M, Kim J, Zaberezhnyy V, Aghili L, Daniel AE, et al. Aging-associated inflammation promotes selection for adaptive oncogenic events in B cell progenitors. J Clin Invest 2015;125:4666-4680. doi: 10. $1172 /$ JCI83024.

[23] Yakoub-Agha I, Mesnil F, Kuentz M, Boiron JM, Ifrah N, Milpied N, et al. Allogeneic marrow stem-cell transplantation from human leukocyte antigen-identical siblings versus human leukocyte antigen-allelic-matched unrelated donors $(10 / 10)$ in patients with standard-risk hematologic malignancy: a prospective study from the French Society of Bone Marrow Transplantation and Cell Therapy. J Clin Oncol 2006;24:5695-5702. doi: 10.1200/JCO.2006.08.0952.

[24] Hu C, Li L. The immunoregulation of mesenchymal stem cells plays a critical role in improving the prognosis of liver transplantation. J Transl Med 2019, 17:412. doi: 10.1186/s12967-019-02167-0.

[25] Mardpour S, Hassani SN, Mardpour S, Sayahpour F, Vosough M, Ai J, et al. Extracellular vesicles derived from human embryonic stem cell-MSCs ameliorate cirrhosis in thioacetamide-induced chronic liver injury. J Cell Physiol 2018;233:9330-9344. doi: 10.1002/jcp.26413.

[26] Huch M, Dorrell C, Boj SF, van Es JH, Li VS, van de Wetering M, et al. In vitro expansion of single Lgr5+ liver stem cells induced by Wnt-driven regeneration. Nature 2013;494:247-250. doi: 10.1038/nature11826.

[27] Messina A, Luce E, Hussein M, Dubart-Kupperschmitt A. Pluripotent-stemcell-derived hepatic cells: Hepatocytes and organoids for liver therapy and regeneration. Cells 2020;9:420. doi: 10.3390/cells9020420. 